\title{
Investigating Radiation Damage in Ceramics: the Role of In Situ Microscopy
}

\author{
K.L. Smith,* G.R. Lumpkin, ${ }^{* *}$ K.R. Whittle, ${ }^{* *}$ M.G. Blackford,** and N.J. Zaluzec*** \\ * Office of Nuclear Science and Technology, Embassy of Australia, 1601 Massachusetts Ave. N.W., \\ Washington D.C., 20036, USA \\ ** Institute of Materials Engineering, Australian Nuclear Science and Technology Organisation, \\ Locked Bag 2001 Kirrawee DC, NSW 2232, Australia \\ *** Materials Division, Argonne National Laboratory, 9700 S. Cass Avenue, Argonne, IL 60439, \\ USA.
}

Radiation damage effects in ceramics are of interest in both current (e.g. nuclear waste forms) and next generation (Gen IV) nuclear technologies (e.g. transmutation targets, inert matrix fuels, waste forms etc.). The mechanisms of radiation damage production and recovery in ceramics often vary dependent on the damage source, e.g., energetic neutrons in reactor systems versus alpha recoil damage in nuclear waste forms. Furthermore, the kinetics of damage recovery are complicated by multiply activated processes and in certain cases, longer-term process may modify the structural state left by irradiation in the short term. Here, we review a selection of data collected by the current authors and associates, which highlight the roles played by in situ microscopy in unraveling the mechanisms of radiation damage in ceramics.

In situ irradiation of a variety of ceramics (e.g. pyrochlores, perovskites, polymorphs of $\mathrm{TiO}_{2}$ and analogues etc.) have been carried out using the IVEM-Tandem Facility at Argonne National Laboratory [1-7]. The IVEM-Tandem Facility is comprised of an intermediate voltage TEM (IVEM), a Hitachi H-9000NAR, interfaced to two ion accelerators (at $30^{\circ}$ to vertical). Specimens were generally prepared by crushing and suspending small fragments on holey carbon coated $\mathrm{Cu}$ grids. Samples were most often, irradiated using $1 \mathrm{MeV} \mathrm{Kr}$ ions at temperatures from 50 to $900 \mathrm{~K}$. Figure 1 shows (a) a bright field (BF) image and (b) selected area diffraction pattern (SADP) of a grain of a typical specimen (in this case $\mathrm{TiO}_{2}$ ) before in situ irradation and (c) the SADP of the same grain after a series of irradiations. Multiple measurements were taken and averaged to ascertain the critical fluence (of particular ions) for amorphisation, $F_{c}$, of a given sample at various temperatures. $F_{c}$ data were then were used to establish the critical temperature, $T_{c}$, of the particular sample, where $T_{c}$ is the temperature at which the recovery process is at least equal to the damage rate (that is the temperature above which a sample can not be amorphised).

IVEM-Tandem data on a range of pyrochlores with different compositions have been compiled and used to develop an empirical model that can predict the $T_{c}$ values for many pyrochlores within +/$80^{\circ} \mathrm{C}[2,6]$. IVEM-Tandem results for specific solid solution series of pyrochlores are informative and will be discussed more fully in the conference presentation.

$\mathrm{La}_{\mathrm{x}} \mathrm{Sr}_{1-3 \mathrm{x} / 2} \mathrm{TiO}_{3}$ perovskites show a non-linear relationship for $T_{c}$ with $\mathrm{x}$ [3]. In combination with other data, in situ TEM suggests that cubic perovskites in the $0<\mathrm{x}<0.2$ composition range are subject to a vacancy assisted recovery mechanism, that may not directly associate with the cubic-tetragonal phase transformation, and that vacancy enhanced amorphisation occurs for both cubic and orthorhombic perovskites in the $\mathrm{x}=\sim 0.2-0.67$ composition range. 
In situ ion irradiation of $\mathrm{TiO}_{2}$ polymorphs, cassiterite $\left(\mathrm{SnO}_{2}\right.$, a rutile analogue) and natural rutile samples with low levels of impurities have been compared with computer simulations $[1,4,5]$. The data suggest that (a) at $50 \mathrm{~K}$, rutile remained crystalline up to a fluence of $5 \times 10^{15}$ ions $\mathrm{cm}^{-2}$, whereas brookite and anatase became amorphous at doses of $8.1 \pm 1.8 \times 10^{15}$ ions $\mathrm{cm}^{-2}$ and $2.3 \pm 0.2 \times 10^{15}$ ions $\mathrm{cm}^{-2}$ respectively, (b) the high radiation tolerance of rutile is related, at least in part, to low energy migration pathways for both $\mathrm{O}$ and $\mathrm{Ti}$, (c) the radiation response of different compounds with the rutile structure can be related to the nature of the cation-anion bonding i.e. covalent/ionic nature, (d) low levels of impurities decrease the radiation resistance of rutile, (e) the radiation response of different $\mathrm{TiO}_{2}$ polymorphs correlates with the number of shared edges, the degree of octahedral distortion, and the crystalline-amorphous volume change of the polymorphs, (f) molecular dynamics simulations of small thermal spikes in each polymorph qualitatively agree with the in situ experiments and $(\mathrm{g})$ the presence of $\mathrm{H}^{+}$impurities may stabilise defects and thus raise the migration barrier for $\mathrm{Ti}$ and $\mathrm{O}$ migration.

As can be seen from the discussion above, data from the IVEM-Tandem Facility has provided crucial insights into the mechanisms of radiation damage in ceramics of relevance to the nuclear fuel cycle and Gen IV nuclear reactors. Unfortunately this facility is due to close in September 2010.

\section{References}

[1] G.R. Lumpkin et al., Amer. Mineral. 95 (2010) 192.

[2] G.R. Lumpkin et al., Chem. Mater. 21 (2009) 2746.

[3] K.L. Smith et al., J. Appl. Phys. Res. 103 (2008) 083531.

[4] N.A. Marks et al., Nuc. Instr. and Meths. in Phys. Res. B. 266 (2008) 2665.

[5] G.R. Lumpkin et al., Phys. Rev. B77 (2008) 1012.

[6] G.R. Lumpkin, Elements 2 (2006) 365.

[7] The authors thank the IVEM-Tandem Facility staff at ANL for assistance during ion irradiations. The Facility is supported as a User Facility by the U.S. DOE Office of Basic Energy Sciences, under Contract No. W-31-10ENG-38. We also acknowledge support from the Access to Major Research Facilities Programme which is a component of the Australian Government International Science Linkages Programme.
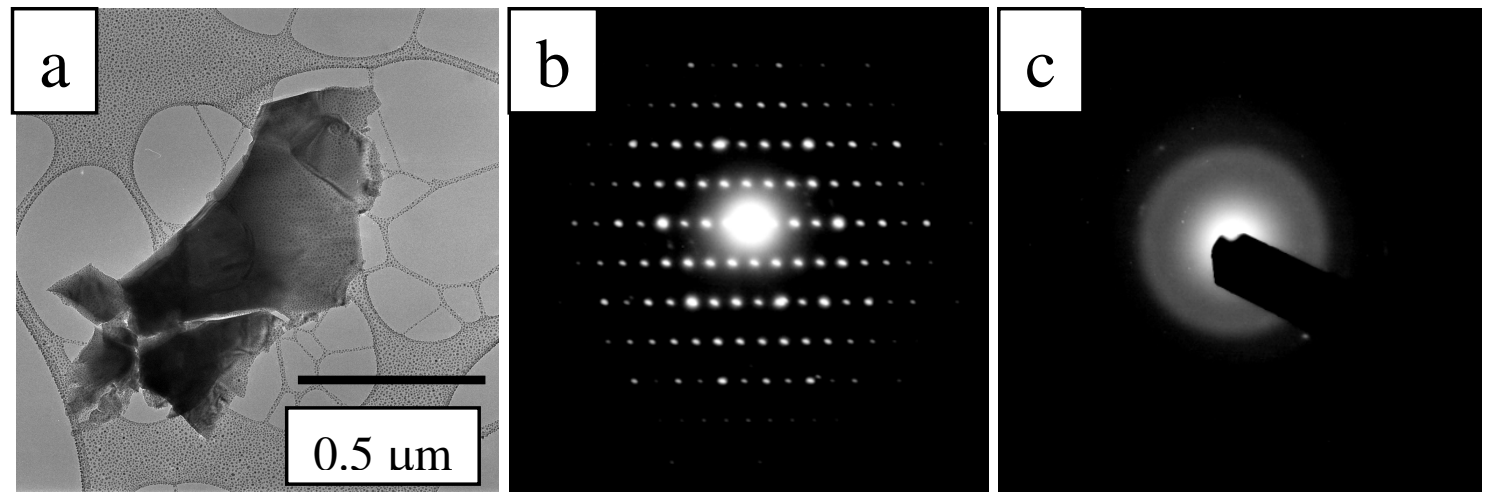

FIG. 1. (a) BF image and (b) SADP of a grain of a typical specimen (in this case $\mathrm{TiO}_{2}$ ) before in situ irradiation and (c) SADP of the same grain after all grains had been rendered amorphous by a series of irradiation steps. 